This article is licensed under the Creative Commons Attribution-NonCommercial 4.0 International License (CC BY-NC) (http://www.karger.com/Services/OpenAccessLicense). Usage and distribution for commercial purposes requires written permission.

\title{
Muir-Torre Syndrome: The Importance of a Detailed Family History
}

\author{
Christopher K.H. Burris $^{a} \quad$ Maria E. Rodriguez ${ }^{a} \quad$ Meisha L. Raven ${ }^{a}$ \\ Devasis N. Reddy ${ }^{a}$ Yaohui G. Xu ${ }^{b}$ Janey L. Wiggs ${ }^{c}$ Heather D. Potter ${ }^{a}$ \\ Daniel M. Albert ${ }^{d}$ \\ aDepartment of Ophthalmology and Visual Sciences, University of Wisconsin, \\ Madison, WI, USA; 'bepartment of Dermatology, University of Wisconsin, \\ Madison, WI, USA; 'Massachusetts Eye and Ear Infirmary, Harvard Medical School, \\ Boston, MA, USA; ${ }^{d}$ Casey Eye Institute, Oregon Health and Science University, \\ Portland, OR, USA
}

\section{Keywords}

Muir-Torre syndrome $\cdot$ Lynch syndrome $\cdot$ Sebaceous carcinoma

\section{Abstract}

Muir-Torre syndrome, a variant of Lynch syndrome or hereditary nonpolyposis colorectal cancer, is an autosomal dominant disease characterized by skin neoplasms (sebaceous or keratoacanthomas) and visceral malignancies. Due to the rarity of the syndrome there are no firm guidelines on how and when to test patients with its typical skin lesions. We describe a case that highlights the importance of a detailed family history.

(C) 2019 The Author(s) 


\section{Case Reports in Ophthalmology}

Case Rep Ophthalmol 2019;10:180-185

DOI: $10.1159 / 000500662$

(c) 2019 The Author(s). Published by S. Karger AG, Basel www.karger.com/cop

Burris et al.: Muir-Torre Syndrome: The Importance of a Detailed Family History

\section{Introduction}

Muir-Torre syndrome (MTS), a variant of Lynch syndrome or hereditary nonpolyposis colorectal cancer, is an autosomal dominant disease characterized by skin neoplasms (sebaceous or keratoacanthomas) and visceral malignancies [1]. Described separately by Muir and Torre in the same year (1967), it was Henry Lynch, in 1981, who realized that these conditions were variants of what would become known as Lynch syndrome [2-4]. Caused by a germline mutation in a DNA mismatch repair gene, the characteristic tumors are associated with microsatellite instability (MSI). Due to the rarity of the syndrome (approximately 200 cases reported before the turn of the century) [5-7] there are no firm guidelines on how and when to test patients with its typical skin lesions.

\section{Case Report}

A 44-year-old man complained of a recurrent bleeding, erythematous, scaly, papillomatous left lower eyelid lesion for 2 years (Fig. 1a). Two prior biopsies of this lesion were diagnosed as skin tags. Past medical history included three fatty tumors removed as a child (left forehead, lower abdomen, and back). Histopathology of the most recent shave biopsy showed skin with an intradermal proliferation of basaloid cells surrounding foamy cells, which formed lobules (Fig. 1b). Many mitotic figures were seen. The epithelium contained hyperkeratosis, parakeratosis, and pagetoid spread of atypical foamy cells, consistent with a well-differentiated sebaceous carcinoma. The remainder of the tumor was removed with Mohs micrographic surgery, and negative margins were confirmed by Oil Red 0 staining. The defect was closed directly. Though his lesion was stage IA (T1N0M0) based on its size, superficial nature, and his clinical examination, due to the patient's young age and family history of colon cancer (2 maternal aunts), there was suspicion for an associated MTS, and immunohistochemistry (IHC) was ordered for the mismatch repair proteins: MLH1, MSH2, MSH6, and PMS2 (Ventana Medical Systems, Tucson, AZ, USA), along with MSI testing (Life Technologies; Carlsbad, CA, USA).

IHC showed a loss of the mismatch repair proteins MSH2 and MSH6 (Fig. 1c). Formalinfixed paraffin-embedded tissue sections were reviewed by a surgical pathologist, who macrodissected tumor and nontumor tissues separately using an automated procedure (Promega, Madison, WI, USA). Multiplex PCR amplification of five mononucleotide microsatellite (BAT25, BAT26, NR21, NR24, and NR27) and two pentanucleotide microsatellite loci (PentaC and PentaD) was performed on the DNA extracted from tumor and nontumor samples. The mononucleotide markers were used for MSI assessment, while the pentanucleotide markers were used to detect potential laboratory errors and/or contamination. Fluorescently labeled amplification products were separated by denaturing electrophoresis and detected using a fluorescent capillary analyzer (Life Technologies). The size profiles of the mononucleotide products were compared directly to those of nontumor tissue. MSI, defined as a change in any length due to insertion or deletion of repeating units within a microsatellite of a tumor compared to nontumor (normal) tissue, was not detected (tumor was MSI-stable). Due to these discordant results, a more detailed patient history was obtained, revealing a family history meeting the Revised Amsterdam II criteria for the diagnosis of Lynch syndrome (Table 1; Fig. 1d) [8]. The patient was referred to a genetic counselor to coordinate testing for a germline 
mutation. A heterozygous germline MSH2 mutation (c.1226_1227del) known to result in the premature truncation of the MSH2 protein at amino acid position 415 was identified, confirming Lynch syndrome (COLARIS ${ }^{\circledR}$, Myriad Genetics, Inc., Salt Lake City, UT, USA).

\section{Discussion}

Due to their rarity, some suggest screening all sebaceous lesions with IHC for loss of mismatch repair proteins [9]. Most of the IHC and MSI research thus far has been on colon tumors and presents a conundrum for the pathologist and clinician trying to apply this to cutaneous sebaceous lesions $[10,11]$. Roberts et al. [11] found IHC in sebaceous neoplasms to have an $85 \%$ sensitivity but only a $48 \%$ specificity and $22 \%$ positive predictive value for MTS. Interestingly, they found a family history of colorectal cancer in two or more family members to have a $92 \%$ sensitivity, $99 \%$ specificity, and $92 \%$ positive predictive value. IHC in our case was effective as a screening tool, showing a loss of staining for the MSH2 and MSH6 proteins. This was confirmed by germline testing, which demonstrated an MSH2 gene abnormality and a normal MSH6 gene. MSH2 and MSH6 proteins form a heterodimer, explaining how loss or abnormality of one could cause a loss of IHC staining for both $[12,13]$. Positive IHC staining confirms the presence of but not the functionality of the mismatch repair proteins, which further complicates interpretation of the results. MSI testing is better at demonstrating a functional loss but has not been approved by the US Food and Drug Administration for this purpose and must be performed with caution. Abbas and Mahalingam [14] have developed a useful diagnostic algorithm for diagnosing MTS in cutaneous sebaceous neoplasms, but their approach does not apply to head and neck tumors. We recommend that all patients with sebaceous neoplasms be screened for MTS. Family history is the most cost-effective screening tool with the highest positive and negative predictive values, and should be utilized first, in order to guide the administration and interpretation of the more expensive confirmatory tests.

\section{Statement of Ethics}

The collection and evaluation of protected patient health information was HIPAA-compliant, and the ethical principles outlined in the Declaration of Helsinki as amended in 2013 were adhered to. The patient gave informed consent to participate in this study, which was approved by our institution's committee on human research.

\section{Disclosure Statement}

The authors have no conflicts of interest to declare. 


\section{Funding Sources}

This work was supported by the National Institutes of Health grant P30-EY016665 (Core Grant for Vision Research) and an unrestricted award from Research to Prevent Blindness.

\section{References}

1 Cohen PR, Kohn SR, Kurzrock R. Association of sebaceous gland tumors and internal malignancy: the MuirTorre syndrome. Am J Med. 1991 May;90(5):606-13.

2 Muir EG, Bell AJ, Barlow KA. Multiple primary carcinomata of the colon, duodenum, and larynx associated with kerato-acanthomata of the face. Br J Surg. 1967 Mar;54(3):191-5.

3 Torre D. Multiple sebaceous tumors. Arch Dermatol. 1968 Nov;98(5):549-51.

4 Lynch HT, Lynch PM, Pester J, Fusaro RM. The cancer family syndrome. Rare cutaneous phenotypic linkage of Torre's syndrome. Arch Intern Med. 1981 Apr;141(5):607-11.

5 South CD, Hampel H, Comeras I, Westman JA, Frankel WL, de la Chapelle A. The frequency of Muir-Torre syndrome among Lynch syndrome families. J Natl Cancer Inst. 2008 Feb;100(4):277-81.

6 Ponti G, Losi L, Di Gregorio C, Roncucci L, Pedroni M, Scarselli A, et al. Identification of Muir-Torre syndrome among patients with sebaceous tumors and keratoacanthomas: role of clinical features, microsatellite instability, and immunohistochemistry. Cancer. 2005 Mar;103(5):1018-25.

7 Akhtar S, Oza KK, Khan SA, Wright J. Muir-Torre syndrome: case report of a patient with concurrent jejunal and ureteral cancer and a review of the literature. J Am Acad Dermatol. 1999 Nov;41(5 Pt 1):681-6.

8 Vasen HF, Watson P, Mecklin JP, Lynch HT. New clinical criteria for hereditary nonpolyposis colorectal cancer (HNPCC, Lynch syndrome) proposed by the International Collaborative group on HNPCC. Gastroenterology. 1999 Jun;116(6):1453-6.

9 Jessup CJ, Redston M, Tilton E, Reimann JD. Importance of universal mismatch repair protein immunohistochemistry in patients with sebaceous neoplasia as an initial screening tool for Muir-Torre syndrome. Hum Pathol. 2016 Mar;49:1-9.

10 Piñol V, Castells A, Andreu M, Castellví-Bel S, Alenda C, Llor X, et al.; Gastrointestinal Oncology Group of the Spanish Gastroenterological Association. Accuracy of revised Bethesda guidelines, microsatellite instability, and immunohistochemistry for the identification of patients with hereditary nonpolyposis colorectal cancer. JAMA. 2005 Apr;293(16):1986-94.

11 Roberts ME, Riegert-Johnson DL, Thomas BC, Thomas CS, Heckman MG, Krishna M, et al. Screening for MuirTorre syndrome using mismatch repair protein immunohistochemistry of sebaceous neoplasms. J Genet Couns. 2013 Jun;22(3):393-405.

12 Arnold A, Payne S, Fisher S, Fricker D, Soloway J, White SM, et al. An individual with Muir-Torre syndrome found to have a pathogenic MSH6 gene mutation. Fam Cancer. 2007;6(3):317-21.

13 Edelmann W, Yang K, Umar A, Heyer J, Lau K, Fan K, et al. Mutation in the mismatch repair gene Msh6 causes cancer susceptibility. Cell. 1997 Nov;91(4):467-77.

14 Abbas 0, Mahalingam M. Cutaneous sebaceous neoplasms as markers of Muir-Torre syndrome: a diagnostic algorithm. J Cutan Pathol. 2009 Jun;36(6):613-9. 


\section{Case Reports in Ophthalmology}
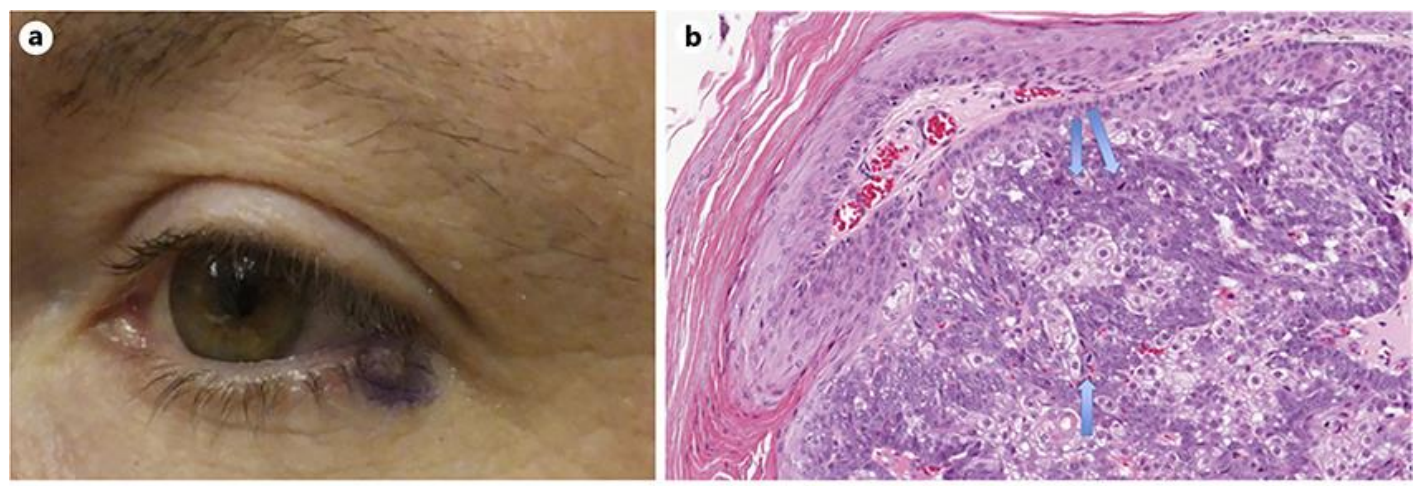
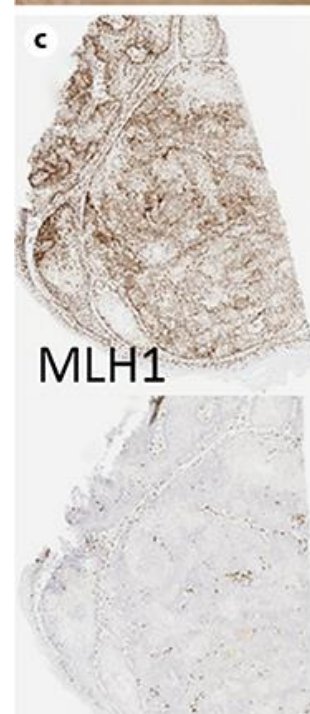

MSH6

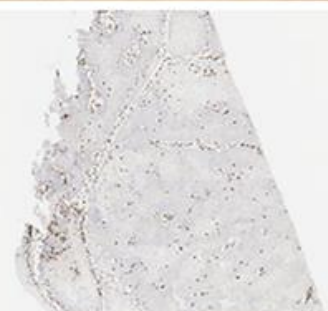

$\mathrm{MSH} 2$

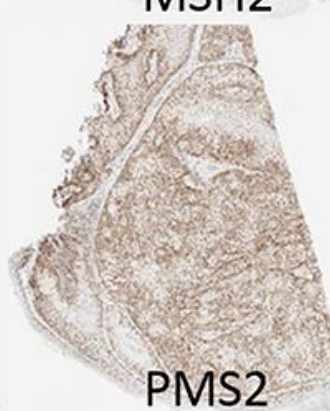

d

I.

II.

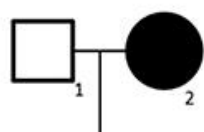

III.
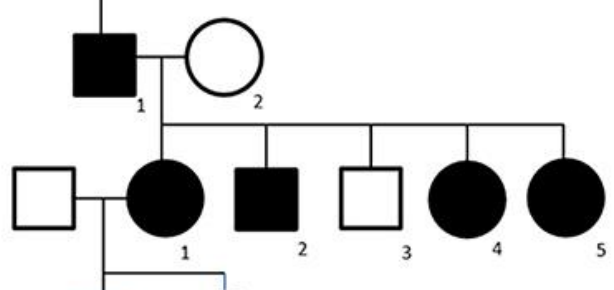

IV.
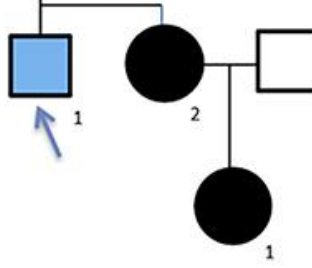

Fig. 1. a Left eye with lower lid lesion marked with a blue surgical marking pen. b Biopsy with intradermal lobules composed of proliferating basaloid cells and foamy cells. Many mitotic figures are seen (arrows), consistent with a well-differentiated sebaceous carcinoma. Hematoxylin and eosin. $\times 20$. c Immunohistochemistry shows the presence of MLH1 and PMS2 and the absence of functional MLH2 and MSH6 (MLH1, MSH2, MSH6, and PMS2. ×6. d Family history (proband designated by arrow). I.2 Uterine cancer, colon cancer (33 years old). II.1 Skin cancer (19 years old), colon cancer ( 45 years old), prostate cancer ( 60 years old). III.1 Endometrial cancer (50 years old), squamous cell carcinoma (64 years old). III.2 Skin cancer. III.4 Endometrial cancer (42 years old), ureter cancer ( 65 years old), colon cancer ( 66 years old), squamous cell carcinoma (68 years old). III.5 Endometrial cancer (64 years old), colon cancer (61 years old). IV.1 Sebaceous carcinoma (45 years old), 3 fatty tumors removed as a child. IV.2 Pre-endometrial cancer (40 years old), pre-skin cancer (41 years old). V.1 Cervical cancer (19 years old). 
Table 1. Revised Amsterdam Criteria (Amsterdam Criteria II) [8]

There should be at least three relatives with an HNPCC-associated cancer (cancer of the colorectum, endometrium, small bowel, ureter, or renal pelvis) and:

One should be a first-degree relative of the other two

At least two successive generations should be affected

At least one should be diagnosed before the age of 50

Familial adenomatous polyposis should be excluded

Tumors should be verified by pathological examination 